\title{
Viajeros ocultistas en el México del siglo XIX
}

José Ricardo Chaves

Universidad Nacional Autónoma de México

\begin{abstract}
Resumen: En este ensayo se revisa el lugar de México en el imaginario ocultista, su vinculación con la tradición europea desde tiempos coloniales por medio del sincretismo hermético de figuras como Carlos de Sigüenza y Góngora y Atanasio Kircher, así como su atractivo para ocultistas notables del siglo XIX como H. P. Blavatsky y Aleister Crowley, quienes real o imaginariamente viajaron a México en la segunda mitad de aquella centuria.
\end{abstract}

ABstract: This essay reviews the place Mexico holds in occultist imagination, its link with European tradition since colonial times by way of the hermetic syncretism of persons such as Carlos de Sigüenza y Góngora and Atanasio Kircher, as well as its attraction for notable occultists in the 19th century like H. P. Blavatsky and Aleister Crowley, who in reality or imagination traveled to Mexico during the second half of that century.

Palabras ClaVe: romanticismo, ocultismo, viajeros ocultistas, México siglo XIX. KEY WORDS: romanticism, occultism, occultists travelers, mexican 19th century.

\section{OCULTISMO, ROMANTICISMO Y SECULARIZACIÓN}

Antes de hablar del lugar de México en la imaginación ocultista, habría que precisar brevemente qué entiendo por ocultismo, palabra cuya acuñación filológica se dio en el siglo XIX, hecho lingüístico que resulta sintomático de que algo nuevo ocurría en el desarrollo europeo de la magia. Como reacción al siglo de la Ilustración y su consecuente secularización del mundo, surgió el romanticismo en un intento de reencantar el mundo, de resacralizarlo. Si bien el romántico es un contrailustrado en muchos de sus temas y contenidos, reconoce el alto nivel intelectual de su adversario, por lo que debe refutarlo con parecido o superior nivel. Es a esta magia posilustrada, corromántica, decimonónica, moderna, a lo que llamo ocultismo. El término se acuñó en francés en la primera mitad del XIX, con autoría atribuida al mago Éliphas Lévi, de gran fama y reconocimiento hasta hoy, en que sus obras siguen publicándose en muchos idiomas. Después Helena P. Blavatsky afinó el término. 
El ocultismo retomó el objetivo de la Filosofía de la Naturaleza de los románticos alemanes de principios de siglo XIX de unir ciencia, poesía y religión en un sistema integrado. Ante el proceso secularizador que sumía en crisis existenciales y de fe a muchos, el ocultista buscó resignificar místicamente la naturaleza sin renunciar a conocerla y encauzarla. Como el científico, no cree en el milagro sino en la ley natural, pero amplía el rango de esta última, pues hay leyes ocultas susceptibles de ser develadas por la razón imaginativa. Esto permite hablar entonces de ciencias ocultas, otra expresión decimonónica que habla de la incorporación del paradigma científico, positivista, al pensar ocultista. En esta línea, resultan elocuentes el mesmerismo, primero, y el espiritismo después, en sus intentos por presentarse al público como ocultismo científico.

Esto tiene que ver con otro rasgo interesante: la secularización religiosa, el desencanto cristiano, el liberalismo, permiten que los grupos ocultistas se desoculten, se muestren a la sociedad, pues buena parte de su gusto por lo secreto se explica por las condiciones religiosas y sociopolíticas en que se habían desarrollado, con la represión inmisericorde de inquisiciones católicas y protestantes, todo lo cual obligaba a ser secretos y subterráneos.

Además de esta vocación cientificista, el ocultismo y el romanticismo comparten un interés multicultural que va más allá de la cultura europea. El descubrimiento y estudio del sánscrito en el siglo XVIII llamó la atención de muchos artistas y sabios europeos hacia la India y, en general, el Oriente. ¿Acaso no escribió Schlegel que "hay que buscar en Oriente lo supremamente romántico"? Las necesidades colonialistas de las potencias europeas también propiciaron un intento por comprender a los vasallos, por estudiar sus textos, esculturas y edificios (aunque estuviesen en ruinas), por apropiarse discursivamente de lo otro subordinado y dar cuenta de ello.

\section{El LUgar de México en la imaginación OCUltista}

México, con sus civilizaciones precolombinas, llamó la atención de los estudiosos y ocultistas europeos durante el siglo XIX, cuando se produjo una renovación de los saberes heterodoxos impulsada en parte por el romanticismo. Sin abandonar el legado mediterráneo (con Egipto como centro mistérico por excelencia), el eclecticismo religioso y cultural del 
ocultismo se dirigió sobre todo al Asia (China, Japón y sobre todo la India), dado el ambiente orientalista del siglo, aunque también se dieron pasos por integrar en sus vastos esquemas multiculturales y sincréticos a las antiguas culturas americanas, en especial los mayas, aunque también aztecas e incas.

Asia, Europa, África, pese a sus diferencias, tenían una historia en común. En cambio, América, desde su descubrimiento durante el Renacimiento, fue el otro por excelencia, culturalmente aislado. Para el ojo europeo, México era parte importante de la América primordial, preeuropea, pero no se sabía muy bien cómo afiliarla a la historia, por lo que de inmediato se acudió al mito, como suele ocurrir en estos casos. Sobre esta presencia mítica en la invención de América escribe Alfonso Reyes:

No son ajenos al Descubrimiento los sueños de Ofir y Catay. La Atlántida, resucitada por los humanistas, trabajó por América. El Cipango y la Antilia representan aquí el paso de la quimera a la realidad, del presagio al hecho. Y todavía después, la mentira — que tantas veces ha guiado oscuramente a los exploradores - seguía haciendo de las suyas, cuando se buscaban en nuestro Continente la Fuente Juvencia, el País de Oro y el Reino de las Amazonas (1971: 11).

En el establecimiento de analogías para intentar comprender lo diferente, una de las cosas que llamaron mucho la atención de los europeos fue la existencia de pirámides tanto en México como en Egipto. Para explicar esta copresencia arquitectónica, los humanistas renacentistas y barrocos extrajeron del oceánico repertorio de mitos mediterráneos nada menos que a la Atlántida, que "trabajó por América", al decir de Reyes, no sólo en cuanto a estímulo para la exploración marítima sino como hipótesis cultural de afinidades entre el Viejo y el Nuevo mundos. Esto se ve muy claro en el erudito jesuita Athanasius Kircher (16021680), quien, ante pirámides a ambos lados del Atlántico, pone de por medio a la Atlántida como extinta patria común. Sobre esto escribe Joscelyn Godwin:

El tratamiento de Kircher sobre el asunto (del Diluvio y el Arca de Noé) no parece tan ingenuo o divertido cuando se lee con conocimiento de la prehistoria real del hombre, tal como fue revelada por H.P. Blavatsky, Rudolf Steiner y otros. Los gigantes, la increíble longevidad, las bestias 
híbridas, los demonios chorreantes de sangre: todo tiene un significado real para el estudiante de lo esotérico. Y sobre todo, el Diluvio no fue fábula sino el recuento del destino de un continente en medio del Atlántico cuyos restos comienzan a salir a la luz (1979: 27).

La influencia de Kircher fue amplia, y la Nueva España no fue la excepción, cuya intelectualidad inquieta

se dejó envolver en la pasión enciclopedista que emanaba de sus páginas. Tanto más atrayente cuanto que los horizontes del sabio alemán, en sus múltiples contradicciones, permitieron a sus admiradores catalizar la crisis entre los nuevos saberes y la ortodoxia; por ello su lectura posibilitó a la cultura novohispana transitar con diferente actitud por caminos ya conocidos, o aventurarse por sendas inéditas hasta entonces (Osorio 1993: XXXIX).

Por medio suyo nociones del hermetismo renacentista se difundieron por la Nueva España, lo que explica en parte el egipcianismo del Primero Sueño de Sor Juana, o la creencia de Carlos de Sigüenza y Góngora en la Atlántida y su estrecha relación con México. Sobre esto escribe Irving A. Leonard en su biografía sobre el sabio novohispano:

Don Carlos estaba firmemente convencido de la existencia del llamado continente o grupo de islas conocido como la Atlántida; estaba seguro de que por allí habían llegado los olmecas a América procedentes del Este. Creía que el resto de las tribus que poblaban el hemisferio occidental habían llegado del Norte y del Noroeste, es decir de Asia [...]. Compartía con su buena amiga sor Juana Inés de la Cruz la convicción de que los mexicas y otras naciones de Anáhuac eran descendientes de Neftuím, hijo de Misraím y sobrino de Cam. Además, don Carlos estaba convencido de que los antepasados de los mexicanos, habiendo salido de Egipto no mucho después de la confusión de lenguas, se dirigieron a América. Esta conclusión se basaba en varios argumentos interesantes: la similitud de mexicanos y egipcios, manifestada en la construcción de pirámides; el empleo de jeroglíficos en el cómputo del tiempo; cierto paralelismo en el atuendo y las costumbres; y también la semejanza de la palabra mexica 'Téotl' con la egipcia 'Theuth'. Todo esto le pareció revelador a don Carlos (1984,: 111-112).

Nótese el eclecticismo de estos recuentos míticos: se combinan las fuentes bíblicas (el Diluvio, el Arca de Noé, la Torre de Babel...) con 
las griegas (la Atlántida) y lo egipcio (dioses y pirámides). Como puede apreciarse, no hay que llegar a corrientes del ocultismo decimonónico como la teosofía de Blavatsky o al movimiento New Age de la segunda mitad del siglo xx para encontrar este tipo de ensamblajes culturales, sincretismos presentes por lo menos desde el Renacimiento. Lo que varía son sus componentes y los asuntos específicos por los que se reúnen las referencias pluriculturales.

Fue así como México, ya desde fines del Renacimiento, fue incorporado al discurso multicultural del hermetismo, que llegaría a convertirse en ocultismo en el siglo XIX, ello por medio del mito de la Atlántida, que permitió vincularlo con Egipto y su tradición mágica. El orientalismo egipcíaco del siglo XIX se vio reforzado después de la llegada de Napoleón a Egipto, y el ocultismo de la época retomó sus conexiones renacentistas de tipo atlante. No obstante el lustre cultural de México, su incorporación plena a las admiradas y sabias civilizaciones antiguas no fue tan lograda porque todavía pesaba mucho la leyenda negra de canibalismo y sacrificios humanos masivos, sobre todo en el caso de los aztecas, aspecto nada compatible con la moral victoriana. Con los mayas fue distinto, pues durante el siglo XIX se descubrieron varias ciudades que generaron gran admiración, además de algunos de sus avances astronómicos y matemáticos, que los llevaron a ser denominados como "los griegos de América", por lo que en su imagen europea se corrió un tupido velo sobre sus aspectos canibalísticos y sacrificiales.

\section{¿Blavatsky en MéXICO?}

$\mathrm{Al}$ recorrer la galería de figuras ocultistas del XIX sin duda una figura descollante es la rusa Helena Petrovna Blavatsky (1831-1891) por varias razones: por la vastedad cultural y mitológica de sus planteamientos, que van más allá de las corrientes mediterráneas y occidentales con la integración de elementos (muchas veces descontextualizados) del budismo y el hinduísmo; por lograr una sistematización de doctrinas dispersas con trasfondo mítico y metafísico, en una dirección moderna, racionalizante y explicativa. Su misma biografía es apasionante, plena de contrastes, de enigmas, triunfos y fracasos. Conocemos a Blavatsky sobre todo como ocultista, pero tiene otras facetas importantes, por ejemplo: como viajera alrededor del mundo (fue amiga del inglés sir Richard F. 
Burton, connotado viajero y traductor de las Mil y Una Noches); como escritora no sólo de libros ocultistas, sino también de crónicas de viajes, de cuentos fantásticos, de una amplia correspondencia, entre otro material interesante; llama la atención también como mujer independiente, desclasada, errante por Europa, Asia, América y el norte de África...

Tras abandonar a su marido cuarentón a sus 18 años, Helena viajó por Grecia, Constantinopla, Siria, Líbano, Egipto, Europa, América toda (la del norte, y supuestamente, la central y la del sur), Asia, en especial Ceilán, la India y el Tíbet. Esta fase viajera es oscura, llena de mitos, iluminaciones, mentiras, hechos reales; es incierta, carece de suficiente documentación y se apoya más en versiones y rumores. Acaba con la llegada de Blavatsky a Nueva York en 1873 veinticinco años después, ya cuarentona. A partir de entonces puede seguirse su pista con documentos (prensa, revistas, periódicos, correspondencia, libros): sus casi cinco años en la ciudad de la Gran Cebolla, hoy de la Gran Manzana, a la que llega desconocida y de la que sale famosa rumbo a la India, vía Inglaterra, con un libro, Isis develada, que la puso en boca (y en ojos) de muchos.

Es en la fase oscura de su biografía (que dura un cuarto de siglo) que se inserta su viaje a México, que habría ocurrido a principios de la década de los cincuenta, entre 1851 y 1852, con poco más de veinte años. Espíritu aventurero no le faltaba, más ahora que se había vuelto una apestada social, una esposa que abandonó a su marido cual Karenina salvaje, en una época y una sociedad nada complacientes al respecto. La lectura de las novelas de James Fenimore Cooper la estimularon para que emprendiera su primer largo viaje por los dominios de los indios americanos. En julio de 1851 llegó a Canadá, donde tuvo oportunidad de indagar sobre prácticas chamánicas y curativas; después, quiso visitar la ciudad de los mormones, Nauvu en Missouri, pero, debido a los disturbios con los vecinos, que llevaron a su destrucción y a la matanza de sus habitantes, Helena siguió a Nueva Orleans, donde investigó sobre el culto vudú. Después:

A través de Texas pasó a México, logrando ver gran parte de este inseguro país, protegida en aquellos arriesgados viajes por su temeraria osadía y por varias personas que de cuando en cuando se interesaban en su favor. Hablaba con especial gratitud de un viejo canadiense, llamado tío Jaime, a quien encontró en Texas, en ocasión en que iba completamente sola. 
La libró de algunos peligros a que entonces estuvo expuesta; y así por una cosa u otra siempre salía bien, aunque parezca milagroso que tan joven como era llevara sin tropezar la independiente vida que había emprendido [...]. Pasaba por aldeas, villas y poblados de toda clase, salvajes y cultos, y no obstante vióse libre de peligro por el hechizo de su propia temeridad y su soberbio desdén por los convencionalismos sociales y toda consideración que estuviera ni aun remotamente relacionada con el 'magnetismo del sexo' (Sinnet 1964: 49).

Estas palabras de Sinnet, el colaborador de Blavatsky por un tiempo, interesan, pues transcriben la información que ella dio directamente para su libro biográfico. No obstante, el conocimiento de México parece vago; se habría limitado tal vez al norte del país. Desde México, Blavatsky habría partido hacia América Central, específicamente Copán, en Honduras, lo que supondría su llegada por el Caribe, pues la entrada a Copán implicaba llegar desde Honduras Británica, hoy Belice. En esto Helena seguía los pasos de sus admirados viajeros Stephens y Catherwood, que pocos años antes habían visitado, estudiado y dibujado espléndidamente ruinas mayas en Centroamérica, Chiapas y Yucatán, y después habían escrito y publicado exitosos libros de viajeros, traducidos a varios idiomas, y quienes aparecen citados muy a menudo en los escritos de Helena. Después de Copán otra vez aparece México, y es aquí donde decide seguir a la India, previa ida a San Francisco.

No hay desarrollos literarios u observaciones de viajera en Blavatsky por su supuesto viaje a México y Centroamérica, a diferencia de lo que ocurre con su estadía en la India, donde hay recuentos personales, descripciones, conocimiento geográfico. De hecho, publicó un libro de crónicas viajeras titulado Por las grutas y selvas del Indostán, tras haberlas sacado antes por entregas en una publicación rusa. Claro, esto lo hace cuando tiene más de cuarenta años, casi cincuenteando, no cuando empieza los veinte años, la edad en que habría visitado México. Discute ideas y teorías, no describe lugares ni personas, excepto en una digresión narrativa en que Blavatsky habla de su rápida visita a Perú, en donde sí se asoma una apreciación personal.

Independientemente de si Blavatsky estuvo o no en México, en todo caso ocupa un lugar en su discurso, y como tema está presente en su dos obras mayores, Isis develada (1877) y La doctrina secreta (1888), aunque en distintos grados de elaboración. En el primer libro, publicado en Nueva York, México aparece en una versión remozada de Kircher, com- 
partiendo lugar en el concierto mistérico universal con Egipto y la India, con Atlántida incluida: "Los aztecas parecen en más de un sentido haber alcanzado a los antiguos egipcios en civilización y refinamiento. Entre ambos pueblos, la magia o la filosofía natural arcana fue cultivada al más alto grado" (1997: 120). Poco antes había afirmado que:

La perfecta identidad de los ritos, ceremonias, tradiciones, y aún los nombres de las deidades, entre los mexicanos y los antiguos babilonios y egipcios, son prueba suficiente de que Sud América fue poblada por una colonia que misteriosamente encontró su camino a través del Atlántico. ¿Cuándo? ¿En qué período? La Historia calla en este punto, pero aquellos que consideran que no hay tradición santificada por los años sin cierto sedimento de verdad en su fondo, creen en la leyenda de la Atlántida (1997: 119).

Más adelante afirma, tras comparar muestras de "arquitectura prehistórica” repartida por todo el mundo (las cuevas hindúes de Ellora en el Dekán, Chichén Itzá en Yucatán y las ruinas de Copán en Centroamérica), que "presentan tales rasgos de semejanza que parece imposible escapar a la convicción de que fueron construidas por pueblos movidos por las mismas ideas religiosas, que habían alcanzado igual nivel de la más alta civilización en artes y ciencias" (121).

En su obra posterior, La doctrina secreta, esta visión conciliatoria e igualitaria de las culturas antiguas (México incluido) cambia, se introducen jerarquías y criterios raciales en un vasto esquema "antropogenético", con razas y subrazas que se suceden y dominan unas a otras, a lo largo de incontables milenios, en una suerte de antropología mítica de gran aliento (en esquemas clasificatorios muy propios del siglo XIX, basta recordar a Hegel, Comte, Marx, Morgan...). En su planteamiento, la Atlántida aparece presidiendo la cuarta raza (entendida esta última palabra casi como civilización) y habría perecido tras tumultuoso cataclismo, como pasó con las razas anteriores. Pero su influencia no se extinguió del todo y sus remanentes culturales y raciales pueden observarse en las culturas precolombinas de México y América Central.

De esta forma, por un remozamiento del hermetismo barroco, el ocultismo blavatskiano integró a las culturas indígenas mexicanas a la gran metahistoria universal, que fueron en el pasado parte del engranaje cósmico por donde evolucionaron las reencarnantes mónadas humanas y lo siguen haciendo en rueda sin fin, hasta su liberación. No fue sino hasta muchas décadas después de Blavatsky que surgieron discursos eso- 
terizantes autóctonos que plantearon una visión diferente de México, no eurocéntrica, de base más chamánica, como la obra de Carlos Castaneda y sus continuadores (pese a todas las objeciones que puedan hacérsele).

\section{La Gran Bestia asciende el Popocatépetl}

Poco menos de cincuenta años después del supuesto viaje de Blavatsky a México, arribó con certeza al país Aleister Crowley, una de las figuras más importantes del ocultismo del siglo $\mathrm{XX}$, aunque buena parte de su perfil tiene que ver más con el fin de siglo XIX, con figuras como Wilde y Yeats, que son sus coetáneos literarios. Crowley, además de mago, se consideraba poeta, y tiene una gran producción al respecto que hasta ahora ha quedado casi en el olvido, opacada por los aspectos ocultistas, sexuales y psicodélicos de su biografía. En la década de los 60 del pasado siglo XX su figura fue rescatada para un nuevo público más amplio como elemento contracultural, como precursor del movimiento de liberación sexual y del uso de drogas. Sus enseñanzas y prácticas ocultistas se retomaron y volvieron a publicarse sus muchos libros de magia, aunque no tanto los de poesía. Sus cuentos y novelas también han vuelto a ver la luz editorial.

A diferencia de Blavatsky, cuyo viaje a México sigue siendo hipotético, en el caso de Crowley sí puede afirmarse con certeza que estuvo aquí por poco más de nueve meses, entre julio de 1900 y abril de 1901, en que viajó a San Francisco para embarcarse al Oriente, la misma ruta que habría seguido antes Madame Blavatsky. Ambos llegaron por primera vez al Oriente, a la India en especial, viajando al Occidente, después de haber estado en México. Para ellos, su camino a la India pasó por México.

En su autobiografía, o como él quiere no sin cierta ironía narcisista, autohagiografía, Crowley da amplia cuenta de su estancia en México, y dedica tres capítulos de 96 a la visita, aparte de más referencias en otras partes del grueso libro. ${ }^{1} \mathrm{Al}$ final del capítulo 22, Crowley, de 25 años, conoce a unos colegas mágicos que acaban de volver de México y, puesto que todos ellos comparten, además del ocultismo, el gusto por escalar montañas, le recomiendan ascender los volcanes aztecas. El joven

\footnotetext{
${ }^{1}$ También hay referencias a México en la poesía de Crowley, como puede verse en su poema "In Vera Cruz Harbour" (cf. Selected Poems 1985).
} 
Crowley les toma la palabra y, tras haber subido las montañas europeas, decide ascender las mexicanas. A diferencia de Blavastky, cuyo interés por visitar México es sobre todo intelectual y mágico, el de Crowley es deportivo en origen, aunque después haya tenido importantes experiencias ocultistas. ${ }^{2}$

En el capítulo 23, Crowley narra su llegada a Nueva York el 6 de julio de 1900 , en medio de una especialmente cálida temporada de calor. Se queda sólo tres días y sigue por tren hacia México. Su primera reacción en la capital es de irritación: por el mal servicio del hotel, por las comidas y las bebidas, pero muy pronto se engancha con el nuevo país, al grado de escribir:

Me encontré a mí mismo espiritualmente en casa con los mexicanos. Ellos desdeñan la industria y el comercio. Tienen a Díaz para hacer su pensamiento político por ellos y condenan lo que él hace. Sus corazones están con las corridas de toros, con las peleas de gallos, con el juego y la lujuria. Su espíritu es valiente y alegre, no ha sido envenenado por la hipocresía y la lucha por la vida (1989: 202).

Le encantan los pájaros, las flores, el paisaje, los colores, la calidad del aire. Alquila una casa por la Alameda y contrata a una sirvienta. Dedica buena parte de su tiempo a sus prácticas y ejercicios mágicos (entre otros, a desarrollar su poder de invisibilidad, en el que dice haber logrado éxito: sale a caminar a la calle con túnica escarlata y corona dorada sin que nadie repare en él), también al sexo ritual, así como a escribir poesía. A veces combina todo esto, por ejemplo: seduce a una mujer con la que pasa haciendo el amor toda un tarde (incluidos ejercicios ocultos durante la relación) y, al regresar a su casa, entra en una suerte de rapto poético de 64 horas de escritura, al final del cual está listo su Tannhäuser, poema dramático al que considerará el principal título de su primer periodo poético.

Conoce al masón mexicano Jesús Medina, se caen bien entre sí. Platican y don Jesús, masón grado 33, queda asombrado por el conocimien-

${ }^{2}$ Cf. The Vision o the Voice, un registro de las exploraciones mágicas de Crowley a partir del sistema de los magos isabelinos John Dee y Edward Nelly, por el que logra ciertas visiones en México y que después, en 1909, continuará en el desierto de Argelia (con sus célebres visiones a partir de rituales de magia homosexual con el poeta Victor Neuburg, padrino literario de Dylan Thomas). 
to cabalista y ocultista de Crowley, que desde hace unos años participa en los círculos mágicos de Inglaterra, sobre todo en la famosa orden de la Golden Dawn. No obstante su militancia esotérica previa, es el mexicano quien inicia al inglés en la masonería formal, quien en poco tiempo alcanza el grado 33, hecho que menciona Crowley varias veces en sus memorias con mucho orgullo. Juntos, Medina y Crowley, fundan una orden nueva, la Lámpara de la Luz Invisible, orden paramasónica de la que se haría cargo el primero tras la partida del segundo. Años después escribiría sobre esto con cierta nostalgia:

La idea general era tener una lámpara siempre encendida en un templo provisto con talismanes apropiados a las fuerzas de la naturaleza elementales, planetarias y zodiacales. Todos los días tenían que realizarse invocaciones con el objeto de hacer de la luz misma un centro consagrado o foco de energía espiritual. Entonces esta luz radiaría y automáticamente iluminaría aquellas mentes que estuvieran listas para recibirla. Aún hoy, el experimento me parece interesante y la concepción sublime. Más bien lamento que haya perdido contacto con Don Jesús; debería conocer más sobre qué pasó (203).

Un último incidente del capítulo es el viaje de Crowley a Iguala, donde los mosquitos le transmiten la malaria. En el capítulo 24 Crowley está de vuelta en la ciudad de México y se hospeda en el Hotel Iturbide. Se mezcla con miembros de las colonias inglesa y norteamericana. Se refiere al alcoholismo del cónsul inglés, adelantándose así al Malcolm Lowry de Bajo el volcán. Frecuenta las casas de juego y recoge la visita a un casino en Tacubaya. Mientras la gente apostaba ocurrió un terremoto, se fue la luz por unos minutos, luego se trajeron velas encendidas y, para sorpresa de todos, el dinero de las apuestas había desaparecido en el ínterin de sombras. Visita Guanajuato y, después, otra vez en la capital, retoma la idea matriz de escalar las montañas. Su sirvienta, tras hacer el amor con su patrón, lo anima a subir los volcanes hechizantes que se observan desde la azotea del edificio.

Después de este capítulo más bien costumbrista, retoma en el número 25 su trabajo mágico y los problemas que esto le genera:

Mientras mi condición mágica me estaba poniendo curiosamente incómodo, yo estaba teniendo éxito más allá de mis expectativas. En el aire puro y seco de México, con su energía espiritual vigorosa e incontamina- 
$\mathrm{da}$, era asombrosamente fácil producir resultados satisfactorios. Pero mi propio éxito de alguna manera me descorazonaba (212).

Finalmente llega de Europa su amigo Eckenstein para la jornada montañista, a quien Crowley esperaba sumido en su crisis existencial y mágica. Crowley le comenta sus problemas con el proceso mágico, a lo que Eckenstein le sugiere que renuncie a la visión romántica y fantasiosa de la magia y se ponga a controlar su mente, a practicar sistemática y seriamente la concentración, piedra básica de cualquier trabajo oculto. Crowley le hace caso y sigue sus instrucciones al tiempo que se preparan para acampar y escalar el Iztaccíhuatl. Durante tres semanas lo recorren por diferentes flancos. Al retornar a Amecameca, visitan al jefe político del lugar, de quien se habían hecho amigos, y éste les comunica con pesar la muerte de la reina Victoria. Ante su asombro, los ingleses estallan de alegría y gozo por la muerte de la soberana, con la esperanza de que con ella termine también la época de mediocridad que su reinado significara. Aquí el autor se explaya en la atmósfera asfixiante y gris de la sociedad victoriana.

Después los viajeros van a Colima, donde les toca presenciar la erupción de un volcán, y más adelante viajan a Toluca, en cuyo Nevado acampan. Luego vendrá el tan esperado ascenso al Popocatépetl, que se realiza en condiciones curiosas, pues los escaladores van acompañados por un reportero del Heraldo, quien había puesto en duda sus hazañas montañísticas, por lo que Eckenstein lo conmina a que los acompañe para que compruebe personalmente el ascenso. El periodista aceptó y los montañistas lo hicieron sufrir en el ascenso; finalmente llegaron a la meta. Después el periodista hizo una crónica de la hazaña deportiva.

Hay un corto viaje a Veracruz. El viaje de regreso a la ciudad de México es descrito con emoción paisajística:

Considero el viaje de regreso de Veracruz a la ciudad el mejor del mundo desde el punto de vista del efecto espectacular; el segundo mejor es del Ganges hasta Darjeeling. Por las primeras cuarenta millas el tren corre entre la jungla tropical, luego el camino de repente empieza a subir y sigue su camino entre desfiladeros subalpinos, con la mole de dieciocho mil pies de altura del Citlaltépetl. El escenario cambia continuamente en carácter conforme uno asciende, y entonces súbitamente uno llega a la meseta, una vastedad casi desierta salvo por los cactus y los magueyes, con los dos conos del Iztaccíhuatl y el Popocatépetl sobresaliendo de ella (220). 
Después Eckenstein parte hacia Inglaterra y Crowley hacia San Francisco, con la intención de continuar al Asia, como siguiendo la ruta invisible que hubiera hecho medio siglo antes Blavatsky. En El Paso, se despide de México, con cierta grandilocuencia:

¡Oh México, mi corazón aún palpita y arde cuando mi recuerdo te trae a mi mente! Por otros países siento más admiración y respeto, pero ninguno de ellos rivaliza con tu fascinación. Tu clima, tus costumbres, tu pueblo, tus extraños paisajes de ensoñador encanto reavivan mi juventud (222).

El aprecio de Crowley por México está anclado en su propio tiempo victoriano y porfirista, en lo que le toca vivir en su viaje de nueve meses, cual embarazo iniciático. Casi no menciona el pasado prehispánico, que no lo encandila, como sí le pasaba a Blavatsky, quien admiraba, más bien románticamente, a un México anclado en un glorioso pasado mítico de corte atlante. Ambos son veinteañeros cuando visitan tierras mexicanas y, tras su estancia, salen para nunca volver al país, rumbo al Asia vía San Francisco. Llegan a la India viajando al Occidente.

La fascinación mágica por México no se agotaría con Blavatsky y Crowley. Seguiría en el siglo xx, aunque ya no con personajes de primera fila en el campo ocultista. Vendrán neoteósofos y seguidores de Gurdjieff y Ouspensky, nazis ocultistas, rosacruces alemanes como Krumm Heller, todo esto antes de la explosión hippie y neochamánica de los años sesenta y setenta. Pero ya estas son otras historias...

BibLIOGRAFÍA

Blavatsky, Helena P. Isis Unveiled. Secrets of the Ancient Wisdom Tradition, Madame Blavatsky's First Work. Illinois: A New Abridgment for Today by Michael Gomes, Quest Books, 1997.

BOURBON, FABIO. Las ciudades perdidas de los mayas. Vida, obra y descubrimientos de Frederick Catherwood. México: Artes de México, 2001.

Cranston, Sylvia. The Extraordinary Life \& Influence of Helena Blavatsky, Founder of the Modern Theosophical Movement. New York: Putnam, 1993.

Crowley, Aleister. Selected Poems. London: Edited and Introduced by Martin Booth Crucible, 1985. 
Crowley, Aleister. The Confessions. An Autohagiography. Arkana, London: Edited by John Symonds and Kenneth Grant, 1989.

- The Vision \& the Voice. With Commentary and Other Papers. Boston: Weiser Books, 1998.

Godwin, Joscelyn. Athanasius Kircher. A Renaissance Man and the Quest for Lost Knowledge. London: Thames and Hudson, 1979.

Leonard, Irving A. Don Carlos de Sigüenza y Góngora. Un sabio mexicano del siglo XVII. México: Fondo de Cultura Económica, 1984.

Osorio Romero, Ignacio. La luz imaginaria. Epistolario de Atanasio Kircher con los novohispanos. México: Universidad Nacional Autónoma de México, 1993.

Reyes, Alfonso. Antología. Selección y prólogo de José Luis Martínez. México: Ediciones Oasis, 1971.

Sinnet, A. P. Incidentes en la vida de la señora Blavatsky. México: Ediciones Voz Informativa, 1964.

Symonds, John. La Gran Bestia. Vida de Aleister Crowley. Madrid: Siruela, 1990.

FECHA DE RECEPCIÓN: 26 de noviembre de 2007.

FECHA DE ACEPTACIÓN: 14 de diciembre de 2007. 